\title{
Sulfide determination in hydrothermal seawater samples using a vibrating gold micro-wire electrode in conjunction with stripping chronopotentiometry
}

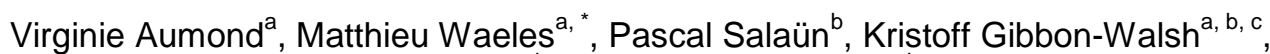 \\ Constant M.G. van den Berg ${ }^{b}$, Pierre-Marie Sarradin ${ }^{d}$, Ricardo D. Riso ${ }^{a}$
}

\footnotetext{
a Université de Bretagne Occidentale, IUEM, Lemar UMR CNRS 6539, Place Copernic, F-29280 Plouzané, France

${ }^{b}$ Ocean Sciences, School of Environmental Sciences, University of Liverpool, Liverpool L69 3GP, UK

${ }^{c}$ RCMO-PROTEE Laboratory, University of Toulon and Var, BP 132, 83957 La Garde, France

d Ifremer, Institut Carnot EDROME, REM/EEP BP 70, F-29280 Plouzané, France

*: Corresponding author : Matthieu Waeles, Tel.: +33 298498696 ; email address : waeles@univ-brest.fr
}

\begin{abstract}
:
A rapid electrochemical stripping chronopotentiometric procedure to determined sulfide in unaltered hydrothermal seawater samples is presented. Sulfide is deposited at $-0.25 \mathrm{~V}(\mathrm{vs} \mathrm{Ag} / \mathrm{AgCl}, \mathrm{KCl} 3 \mathrm{M})$ at a vibrating gold microwire and then stripped through the application of a reductive constant current (typically $-2 \mu \mathrm{A}$ ). The hydrodynamic conditions are modulated by vibration allowing a short deposition step, which is shown here to be necessary to minimize $\mathrm{H}_{2} \mathrm{~S}$ volatilization. The limit of detection (LOD) is $30 \mathrm{nM}$ after a deposition step of $7 \mathrm{~s}$. This LOD is in the same range as the most sensitive cathodic voltammetric technique using a mercury drop electrode and is well below those reported previously for other electrodes capable of being implemented in situ.
\end{abstract}

\section{Graphical abstract :}

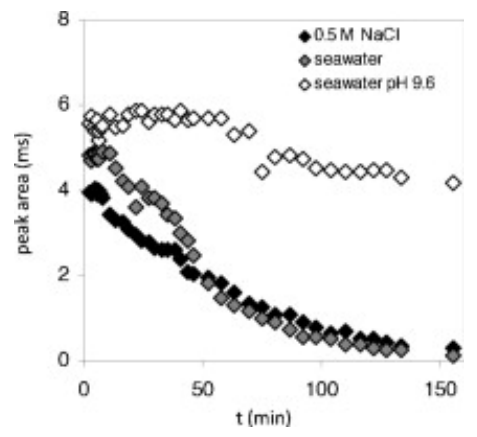

Keywords: Sulfide ; Stripping chronopotentiometry ; Vibrating electrode ; Gold ; Seawater ; Hydrothermal 


\section{1. Introduction}

2 Free sulfide $\left(\mathrm{H}_{2} \mathrm{~S}, \mathrm{HS}^{-}, \mathrm{S}^{2-}\right)$ is an exceedingly important substance in the aquatic environment.

3 It is both a potent poison for many aquatic organisms, even at concentrations in the

4 micromolar range [1] and an energy source for sulfur bacterial symbionts found in

5 chemosynthetic communities [2,3]. Due to its strong affinity for most metal ions, sulfide can

6 be stabilized through the formation of complexes and precipitates, thus acting as an

7 important chelate in the regulation of metal availability to organisms [4-7].

8 Various methods have been developed for measuring sulfide in seawater.

9 Spectrophotometric detection of methylene blue is the usual technique and allows sulfide

10 measurements in the $1-1000 \mu \mathrm{M}$ range. It is based on the specific reaction between free

11 sulfide and $\mathrm{N}, \mathrm{N}$-dimethyl-p-phenylenediamine [8] and in conjunction with flow injection

12 analysis (FIA) this technique can be implemented in-situ [9-11]. Gas chromatography (GC) is

13 currently the most sensitive technique; using a liquid nitrogen-cooled trapping and a flame

14 photometric detection, Radford-Knoery and Cutter [12] developed a GC method allowing

15 total dissolved sulfide determination (i.e. free sulfide + complexed sulfide) with a detection

16 limit of $0.5 \mathrm{pM}$.

17 However, because of their low-cost and compactness, electrochemical techniques represent

18 a prudent alternative, with the capability to be implemented in-situ. Direct monitoring at

19 levels in the micromolar range has been conducted by (i) potentiometry with the combined

20 use of a $\mathrm{pH}$ electrode and $\mathrm{a} \mathrm{Ag} / \mathrm{Ag}_{2} \mathrm{~S}$ ion-selective electrode [13]; (ii) amperometry with a

21 glass-coated platinum electrode [14] or (iii) voltammetry with a solid-state gold-amalgam

$22(\mathrm{Au} / \mathrm{Hg})$ wire $[5,15]$ or a bismuth film wire electrode [16]. For sulfide determination below 1

$23 \mu \mathrm{M}$, a preconcentration step (i.e. stripping technique) is required. Cathodic stripping 
1 voltammetry (CSV) is the most widely used technique and has been mostly associated with a

2 mercury drop electrode [e.g. 17,18]. Al Farawati and Van den Berg [19] showed however,

3 that waste metallic mercury, which is produced by the mercury drop system, rapidly

4 precipitates with free sulfide thus leading to uncertainties in its determination. By using a

5 flow-analysis system, they solved this problem reporting a $0.5 \mathrm{nM}$ detection limit for a $60 \mathrm{~s}$

6 deposition time. Notably, when using CSV with a mercury drop, purging with an inert gas is

7 necessary to remove dissolved oxygen. Such addition of a gas can lead to perturbations of

8 the medium with potential loss of $\mathrm{H}_{2} \mathrm{~S}, \mathrm{pH}$ change and corresponding variations of chemical

9 equilibrium, and a decrease of sample throughput due to a minimum of 5 min purging per

10 sample. CSV at a bismuth film electrode wire has also been investigated [16] but the

11 reported detection limit $(1 \mu \mathrm{M}$ after $30 \mathrm{~s}$ of preconcentration) does not offer any

12 improvement when compared to direct determination by linear scan voltammetry or square-

13 wave voltammetry [15].

14 In this study, we investigated the suitability of a vibrating gold microwire electrode (VGME)

15 for measuring sulfide in seawater. The hydrodynamic modulation by vibration of the working

16 electrode results in a very stable convection conditions [20] and a thin diffusion layer ( 2

$17 \mu \mathrm{m})$ [21,22]. Moreover this kind of system has proved its potential for in-situ analysis [22].

18 Here the VGME electrode was tested in conjunction with cathodic stripping

19 chronopotentiometry (SCP). In SCP, the preconcentration step is the same as in stripping

20 voltammetry, whereas the stripping step is performed through the application of a constant

21 oxidative or reductive current [23]. SCP has been used for the determination of metals and

22 metalloids in seawater at low concentrations [24-29]. Detection of sulfide by SCP was

23 recently reported in waste water using a macroporous mercury-film electrode [30]. Although

24 a low detection limit is reported $(\sim 20 \mathrm{nM})$, measurements take several minutes and the 
1 procedure requires a medium exchange before the stripping step which limits its potential

2 application for in-situ analysis. We report here for the first time the determination of sulfide

3 in seawater at a VGME by SCP. The method does not require medium exchange, deaeration

4 or reagent addition and is potentially applicable for on-board analysis immediately after

5 sampling or even in-situ analysis.

6

7 2. Experimental

8

9

10

11

12

14

16

17

18

19

\subsection{Reagents}

Water used to prepare reagents and preliminary working solutions was ultrapure deionised water $\left(>18 \mathrm{M} \Omega\right.$ ) from a Milli-Q Element system (Millipore ${ }^{\circledR}$, St Quentin, France). The HS stock solution ( 70 mM) was prepared from $\mathrm{Na}_{2} \mathrm{~S} .9 \mathrm{H}_{2} \mathrm{O}$ (Sigma), stored at $4{ }^{\circ} \mathrm{C}$ and standardized every 2 weeks by iodometric titration [8,31]. From this stock solution, working solutions (in the range $0.03-10 \mathrm{mM}$ ) were prepared daily, just before the beginning of a set of experiment. A pH 9.6 buffer was prepared with $0.01 \mathrm{M} \mathrm{NH}_{4} \mathrm{OH}$ and $0.01 \mathrm{M} \mathrm{NH}_{4} \mathrm{Cl}$ (Fluka). A $0.5 \mathrm{M} \mathrm{H}_{2} \mathrm{SO}_{4}$ solution (Fluka) was used for electrode conditioning. For interference experiments, different aqueous standard stock solutions were freshly prepared: Gluthatione (Sigma-Aldrich) $5 \mathrm{mM}$, thioacetic acid (Fluka) $14 \mu \mathrm{M}$ and elemental sulfur (Pestanal, Sigma) 3.2 mM. Due to its low solubility in water, elemental sulfur was first dissolved into $10 \mathrm{~mL}$ THF and $100 \mathrm{~mL}$ ethanol. A $0.5 \mathrm{M} \mathrm{NaCl}$ (Fluka) solution was also prepared for the dilution of some samples. 


\subsection{Sample collection}

2 For optimization of the technique, various tests using seawater were performed on (i) a

3 coastal seawater sample collected in the Bay of Brest and (ii) hydrothermal samples

4 collected at Lucky Strike vent field (Mid-Atlantic Ridge, $37.3^{\circ} \mathrm{N}$ ) in the seawater-

5 hydrothermal mixing zone (temperature range $4-70^{\circ} \mathrm{C}$ ) during the MoMARSAT 2010 cruise

6 (see [32] for the description of the sampling sites and procedures). Hydrothermal seawater

7 samples were immediately stored at $-20^{\circ} \mathrm{C}$ with minimum headspace as previously

8 recommended for thioarsenic species [33] until optimization tests at the laboratory. The

9 usual way to preserve sulfide is to create a precipitation of total sulfide by adding an excess

10 of $\mathrm{Zn}$ ion [34]. However, freezing was selected here in order to minimize changes in chemical

11 equilibriums and therefore analyse samples which are as close as possible to realistic,

12 natural conditions. Mg concentrations were measured in these hydrothermal samples in

13 order to know the degree of dilution of seawater with the hydrothermal fluid. They were

14 determined by ICP-OES (Ultima 2, Horiba Jobin Yvon, Pôle Spectrométrie Océan) with a

15 precision under $0.5 \%$. Obtained concentrations were in the range of $45-53 \mathrm{mM}$ indicating

16 that these samples contained between 85 and 100\% seawater. Fe and $\mathrm{Mn}$ were also

17 measured by ICP-OES (precision <1\%); concentrations were in the range 1.5-5.7 $\mu \mathrm{M}$ and 16-

$1855 \mu \mathrm{M}$, respectively.

\subsection{Instrumentation}

21 Electrochemical instrumentation was a $\mu$ Autolab(III) potentiostat and a IME 663 interface 22 from Metrohm (Switzerland). Data was processed with GPES 4.9 software. A $50 \mathrm{~mL}$ three23 electrode cell was used containing the working electrode (WE), a counter electrode 24 consisting of a $200 \mu \mathrm{m}$ iridium wire (from Goodfellow, UK), heat-sealed in a propylene 
1 pipette tip, $3 \mathrm{~mm}$ protruding; the reference electrode was a glass $\mathrm{Ag} / \mathrm{AgCl} / \mathrm{KCl}(3 \mathrm{M})$. The WE

2 was a bare gold microwire electrode, prepared as described by Nyholm and Wikmark [35]

3 and Gibbon-Walsh et al. [36], briefly: a $10 \mu \mathrm{m}$ diameter gold microwire (99.99\%, hard,

4 Goodfellow) was heat-sealed in a $100 \mu \mathrm{L}$ polypropylene pipette tip with about $0.5 \mathrm{~mm}$

5 protruding. This tip was then fitted onto a $1 \mathrm{~mL}$ polypropylene pipette tip, which had a

6 vibrator incorporated and an insulated connecting single core electrical cable protruding $\sim 1$

$7 \mathrm{~cm}$ at the bottom, which made contact with the WE. The cell was PTFE for analyses and a

8 separate, plastic, cell was used for electrode conditioning in $0.5 \mathrm{M} \mathrm{H}_{2} \mathrm{SO}_{4}$

\subsection{Electrode conditioning}

11 The WE was conditioned each day before a set of experiments in $\mathrm{H}_{2} \mathrm{SO}_{4} 0.5 \mathrm{M}$ using cyclic 12 voltammetry (5 scans) from -0.2 to $1.5 \mathrm{~V}\left(105 \mathrm{mV} \mathrm{s}{ }^{-1}\right)$. The symmetry and area of the 13 reduction peak of the gold oxide monolayer were used to check the behavior of the 14 electrode and monitor the gold surface, respectively [37].

\subsection{Sulfide determination by stripping chronopotentiometry}

17 Stripping chronopotentiometry (SCP) consists of 2 steps: electrolysis and stripping. During 18 electrolysis (also named deposition step), $\mathrm{HS}^{-}$is deposited at the gold wire by applying an oxidizing potential. In this condition, $\mathrm{Au}(0)$ at the electrode surface is oxidized to $\mathrm{Au}(\mathrm{III})$ with

20 which the $\mathrm{HS}^{-}$reacts as follows [16]:

$$
3 H S^{-}+2 A \underset{\check{2}}{\stackrel{1}{\rightleftarrows}} A u_{2} S_{3}+3 H^{+}+6 e^{-}
$$


1 The amount of deposited sulfide $\left(n_{s}\right)$ is determined by Fick's diffusion laws assuming a

2 constant diffusion layer size at any time during the deposition step (eq. 1):

where $\left[\mathrm{HS}^{-}\right]\left(\mathrm{mol} \mathrm{cm}^{-3}\right)$ is the bulk concentration of sulfide, $\mathrm{D}\left(\mathrm{cm}^{2} \mathrm{~s}^{-1}\right)$ its diffusion coefficient, $\delta_{\mathrm{e}}(\mathrm{cm})$ the diffusion layer thickness under vibrated conditions, $\mathrm{A}\left(\mathrm{cm}^{2}\right)$ the electrode surface area, and $t_{d}(s)$ the deposition time.

During the stripping step, the application of a constant reductive current leads to the reduction of $\mathrm{Au}$ (III) (direction 2 in the above reaction). The amount of sulfide is directly related to the time corresponding to the reduction of $A u(I I I)$ to $A u(0)$ which is obtained by monitoring the variation of the WE potential $(E)$ as a function of time (t). From this chronopotentiogram, a derivative curve (i.e. $\mathrm{dt} / \mathrm{dE} v s \mathrm{E}$ ) is established where the amount of stripped material is proportional to the peak area. It has been shown that the capacitive charging current is effectively eliminated by this signal treatment [38]. The peak area corresponds to the time used to strip the analyte from the electrode ( $t_{s}$ in $m s$ ) and can be expressed as follows [39]:

$$
t_{S}=k \frac{\left[H S^{-}\right]}{\left(i_{S}-i_{0}\right)} \quad \text { (eq 2) }
$$

where $\mathrm{k}$ is a mass transfer coefficient that incorporates $\mathrm{D}$ and $\delta_{\mathrm{e}}, \mathrm{i}_{\mathrm{s}}$ the magnitude of the applied current and $\mathrm{i}_{0}$ the amount of this current lost by side reactions due to diffusion of reducible species to the electrode and/or competing reactions at the electrode substrate surface. Assuming the condition $i_{s} \gg i_{0}$ is fulfilled during stripping, small variations in the diffusion layer will not noticeably affect $t_{s}$ in this respect [40].

It is worth noting that both directions 1 and 2 in the above reaction should be considered as a simplified mechanism. Recent studies [41] have shown that the deposition and stripping 
1 mechanisms are more complexes than previously thought. Anodic processes consist mainly

2 in underpotential deposition of sulfur and possible formation of a sulfur multilayer at the

3 electrode surface competing with the formation of soluble polysulfides. Cathodic processes

4 comprise dissolution of the deposited sulfur-containing layer and formation of insoluble

5 polysulfides with incorporation of $\mathrm{Na}^{+}$ion. Multiple peaks can be observed depending on

6 the conditions. The mechanistic aspect of the deposition and stripping of sulfur is however

7 beyond the scope of this paper.

8 Each measurement consisted in two successive SCP scans: an analytical scan with the

9 deposition-stripping steps and a background scan, which is similar to the analytical scan, but

10 with only a $1 \mathrm{~s}$ deposition step. The background scan is then subtracted from the analytical

11 scan to give a background corrected scan with well defined peaks, especially at low

12 concentration. Prior to each analytical scan, the electrode was conditioned (cleaned), under

13 vibration, using a potential at $-1.1 \mathrm{~V}$ for $10 \mathrm{~s}$. A typical procedure for the analytical scan was

14 as follows: vibrator on, $-1.1 \vee(10 \mathrm{~s}),-0.25 \vee(7 \mathrm{~s})$, vibrator off, $1 \mathrm{~s}$ equilibration, stripping

15 from -0.25 to $-1.1 \vee(-2 \mu \mathrm{A})$. For the background scan: vibrator on, $-0.25 \vee(1 \mathrm{~s})$, vibrator off,

$161 \mathrm{~s}$ equilibration, stripping from -0.25 to $-1.1 \mathrm{~V}(-2 \mu \mathrm{A})$. The measurements, background 17 subtraction and peak analysis were fully automated through the Project option of the GPES 18 software.

\section{3. Results and discussion}

\section{$21 \quad 3.1$ Instability of the sulfide species}

22 Various oxidants in seawater, such as dissolved oxygen [42,43], hydrogen peroxide [44] or 23 iodate [45] are known to react with free sulfide in a matter of hours. Purging of the sample 24 (with $\mathrm{N}_{2}$ or $\mathrm{Ar}$ ), as often required with voltammetric techniques to remove dissolved oxygen, 
1 cannot help to solve this problem because such a procedure removes free sulfide $[12,46]$.

2 Conditions created by some techniques can also enhance the rate loss of free sulfide (e.g. by

3 electromotive force [47]). For instance, when using a mercury drop electrode, the sulfide

4 peak is rapidly lost (few minutes) due to precipitation with mercury present in the

5 voltammetric cell [19]. Recently, DeLeon et al. [48] demonstrated that the loss of sulfide for

6 samples exposed to air is not due to oxidation but to $\mathrm{H}_{2} \mathrm{~S}$ volatilization. They reported half

7 lives of few minutes and tens of seconds in samples exposed to air and samples bubbled

8 with nitrogen respectively.

9 The stability of the sulfide peak at the gold microwire electrode was tested here in various

10 non deoxygenated media: (i) $0.5 \mathrm{M} \mathrm{NaCl}$, (ii) natural coastal seawater and (iii) natural coastal

11 seawater buffered at $\mathrm{pH} 9.6$ (Fig 1a). For this purpose, repetitive electrolysis-stripping cycles

12 were undertaken in solutions exposed to air and spiked with $13 \mu \mathrm{M}$ of sulfide. For $\mathrm{NaCl}$

$13(0.5 \mathrm{M})$ and natural seawater, the sulfide peak was stable for $\sim 10 \mathrm{~min}$ after which a decrease

14 was observed, with $50 \%$ of the initial signal being lost after $\sim 40 \mathrm{~min}$. As illustrated in figure

$151 \mathrm{~b}$, the loss rate constants were estimated to $1.8 \% \mathrm{~min}^{-1}$ for $\mathrm{NaCl} 0.5 \mathrm{M}$ and $2.6 \% \mathrm{~min}^{-1}$ for

16 seawater. For seawater buffered at $\mathrm{pH} 9.6$, the peak stability was much greater ( $1 \mathrm{~h})$ with

$1720 \%$ loss after $2 \mathrm{~h}$. Following the hypothesis that a first order kinetic also occurs in seawater

18 buffered at $\mathrm{pH} 9.6$, the rate of sulfide loss was $\sim 0.2 \% \mathrm{~min}^{-1}$. The half-life of sulfide in $\mathrm{pH} 8$

19 seawater in oxidising conditions and samples not exposed to air is $\sim 26 \mathrm{~h}$ [47]. Our data, with

20 significant losses after only a few minutes (half life of $\sim 30 \mathrm{~min}$ ) and their $\mathrm{pH}$ dependence

21 suggest that the loss is due to $\mathrm{H}_{2} \mathrm{~S}$ volatilization rather than oxidation and is independent of

22 a potential loss of sensor sensitivity. Analysis of sulfide in natural seawater (including

23 standard additions) can thus be done if achieved within few minutes. Optimisation of the

24 various parameters consisted in decreasing the overall measurement time. 


\section{$2 \quad 3.2$ Optimization of the electrochemical parameters.}

3 Optimisation of the electrochemical parameters was done using an unaltered hydrothermal

4 stock sample containing approximately $0.5 \mu \mathrm{M}$ of sulfide. From this stock sample, different

5 aliquots of $\sim 15 \mathrm{~mL}$ were used and the whole optimisation procedure presented below was

6 realized within 2 days, in order to avoid strong changes with respect to the analyte. The free

7 sulfide reduction peak was located at approximately $-1.0 \mathrm{~V}$ vs $\mathrm{Ag} / \mathrm{AgCl}(\mathrm{KCl}, 3 \mathrm{M})$. The

8 influence of the deposition potential $\left(E_{d}\right)$ was tested from $-0.9 \vee$ to $+0.1 \vee$ (Figure 2a). The

9 signal response strongly increased when $E_{d}$ was varied between -0.75 and $-0.25 V$ whilst

10 decreasing at more positive potentials. The reasons for such a decrease could be due to the

11 reactions of various species present in the sample either: (1) Blocking of the gold electrode

12 surface following Fe(II) and $\mathrm{Mn}$ (II) oxidation to their more oxidised, insoluble, precipitates in

13 Fe and $\mathrm{Mn}$ rich waters [36] as it is the case for the hydrothermal samples used here.

14 However, a similar decrease was observed in coastal seawater (i.e. containing low levels of

15 Fe and $\mathrm{Mn}$ ) spiked with free sulfide. Or (2), Formation of polysulfide at the working electrode

16 occurs at more positive anodic potentials (>-0.2 V, [41]) and result in several cathodic peaks

17 [49] located in the region of the sulfide signal (as the one observed here at $\sim-0.8 \mathrm{~V}$, Fig. $2 \mathrm{~b}$ ).

18 The formation of these species at the electrode could reduce the amount of deposited

19 sulfide. Taking the above evolution of the sulfide signal into account, a deposition potential

20 of $-0.25 \mathrm{~V}$ was chosen for subsequent experiments.

21 The effect of the intensity of the stripping current $\left(i_{s}\right)$ was studied with the aim of obtaining a

22 sensitive and reproducible signal. As illustrated in figure 3 , the signal $\left(t_{s}\right)$ strongly increased

23 from $1 \mathrm{~ms}$ to $\sim 500 \mathrm{~ms}$ by varying the stripping current from $-3 \mu \mathrm{A}$ to $-0.2 \mu \mathrm{A}$. For the sample

24 used for optimisation, the signal was reproducible over the range of tested values. However, 
1 for many other samples, especially those having relatively high sulfide content $(>1 \mu \mathrm{M})$, an

2 irreproducible signal was often observed for stripping currents under $1 \mu \mathrm{A}$ (absolute value).

3 As illustrated in figure $3 b$, the sulfide signal was close to the negative potential limit of the

4 electrode due to reduction of cations from the electrolyte (mainly $\mathrm{Na}^{+}$) or water $\left(\mathrm{H}^{+} / \mathrm{H}_{2} \mathrm{O}\right.$ )

5 [50]. A reduction current of $-2 \mu \mathrm{A}$ was found to be generally satisfactory (Fig. $3 \mathrm{c}$ ) and was

6 therefore selected for further tests.

\subsection{Linear response of sulfide signal}

9 The linear range of signal response was examined through standard additions of free sulfide

10 to an unaltered hydrothermal sample. The peak area was found to increase nearly linearly

11 over the range $0-20 \mu \mathrm{M}$ (Fig. 4a), however, the shape of the signal changed over the course

12 of the experiment. A loss of symmetry was observed and a narrow peak emerged from the

13 initial signal after addition of $\sim 5 \mu \mathrm{M}$. This narrow peak was also observed at increased

14 deposition time indicating that the development of this peak depends on the amount of deposited sulfide. According to Gao et al. [49] and Bura-Nakic et al. [41], this is related to the

formation of polysulfide adlayers on the gold. Whatever the nature of the sulfide species,

17 the conditioning of the electrodes at $-1.1 \mathrm{~V}$ for $10 \mathrm{~s}$ was always efficient in removing the

18 adsorbed species. This is consistent with previous observations that desorption occurs

19 through reductive dissolution at potentials below -0.9 $\vee[41,51]$.

20 Using our microwire electrode (real surface area of $0.85 \mathrm{~mm}^{2}$ including surface roughness;

21 estimated from [37]), the peak-shape changed for signals over $10 \mathrm{~ms}$. Figure $4 \mathrm{~b}$ illustrates

22 however, that good linearity is achieved when standards additions are conducted before the

23 change of the peak-shape. For quantification of sulfide concentrations, it is necessary to 
1 dilute samples with a $0.5 \mathrm{M} \mathrm{NaCl}$ solution prior to calibration in order to stay within the

2 linear range of the method.

3

\section{$4 \quad 3.4$ Limit of detection, reproducibility and electrode stability}

5 The limit of detection (LOD) was evaluated from $3 x$ the standard deviation (SD) of 9 measurements in an unaltered hydrothermal sample containing $58 \mathrm{nM}$ sulfide. For a deposition time of $7 \mathrm{~s}$, the SD was $20 \%$ giving a LOD of around $30 \mathrm{nM}$. By increasing the deposition time to $60 \mathrm{~s}$, the LOD was lowered to $10 \mathrm{nM}(\mathrm{SD}=6 \%, \mathrm{n}=8)$. Detection of lower concentrations was tested with a deposition time of $240 \mathrm{~s}$. For a sample containing $6 \mathrm{nM}$,

10 the LOD for a deposition time of $240 \mathrm{~s}$ was $3 \mathrm{nM}(\mathrm{SD}=15 \%, \mathrm{n}=4)$. This deposition time 11 represents however an upper limit since quantification by standard addition must be carried out within a few minutes.

The reproducibility $(n=5)$ was assessed on two unaltered hydrothermal samples containing

14 different amount of sulfide. For the sample containing $0.18 \mu \mathrm{M}$ the reproducibility was $15 \%$

$15(0.18 \pm 0.3 \mu \mathrm{M})$. Due to its high concentration, the sample containing $15.1 \mu \mathrm{M}$ of sulfide was diluted in ultrapure water containing $0.5 \mathrm{M} \mathrm{NaCl}$. Aliquots were prepared before each analysis by diluting ten times the original sample. An example of this analysis is illustrated in fig. 5 . The obtained reproducibility was $11 \%(15.1 \pm 1.7 \mu \mathrm{M})$. In absence of certified reference material for such chemical species, sulfide concentrations were measured after adding a known amount of sulfide in (i) a $\mathrm{NaCl} 0.5 \mathrm{M}$ solution and (ii)

21 an hydrothermal sample in which free sulfide was first let to volatilize. Obtained concentrations gave recoveries of $90 \pm 8 \%(n=3)$ and $104 \pm 9 \%(n=3)$, respectively.

23 It is worth noting that the same electrode was used continuously over a period of 6 month 24 highlighting its long stability when used with the recommended procedure. 


\subsection{Interferences}

3 On the mercury electrode, elemental sulfur $\left(S^{0}\right)$ and organic thiols are known to produce

4 cathodic peaks that interfere with sulfide [21]. Additions of thioacetic acid $\left(\mathrm{CH}_{3} \mathrm{COSH}\right)$ and of $5 \quad S^{0}$ and glutathione (GSH) which are potentially present in the proximity of hydrothermal organisms $[52,53]$ were tested here in order to examine their influence on the sulfide signal

7 at the gold microwire electrode. These species were added in a non buffered seawater

8 sample containing $1.0 \mu \mathrm{M}$ sulfide at ratios of $1: 1,10: 1$ and 100:1 (Table 1 ). The experiment

9 was carried out quickly (within five minutes) to avoid sulfide loss by volatilization. No clear

10 differences were observed after $S^{0}$ addition suggesting that it does not interfere with sulfide.

11 On the other hand, addition of $\mathrm{CH}_{3} \mathrm{COSH}$ and $\mathrm{GSH}$ caused a drop in the signal. For $\mathrm{CH}_{3} \mathrm{COSH}$, 12 the drop was $\sim 70 \%$ at the $10: 1$ ratio. For $\mathrm{GSH}, \sim 90 \%$ of the signal was lost at the 1:1 ratio.

13 Considering the low pKa of these compounds (pka=3.3 and $p a_{1}=3.6$ for $\mathrm{CH}_{3} \mathrm{COSH}$ and GSH,

14 respectively), acido-basic reaction with hydrogenosulfide may enhance $\mathrm{H}_{2} \mathrm{~S}$ formation and consequently, loss. In any case, the added species were not detected under the electrochemical conditions optimized for sulfide quantification at the VGME.

\section{Conclusions}

We have presented a stripping chronopotentiometric (SCP) method using a vibrating gold microwire electrode for sulfide quantification in unaltered seawater and hydrothermal

21 samples. The detection limit ( $30 \mathrm{nM}$ for a $7 \mathrm{~s}$ deposition time) is lower than those reported

22 for non-stripping techniques and is close to the most sensitive voltammetric method [19]

23 based on a Hg drop electrode (LOD: $0.5 \mathrm{nM}$ for a $60 \mathrm{~s}$ deposition time). Compared to the $\mathrm{Hg}$

24 drop, the strong advantage of the vibrating gold microwire electrode is its capability to be 
1 implemented in-situ [22]. It is intended to use this method as part of the development of an

in-situ analyzer for deep sea hydrothermal environments.

\section{Acknowledgments}

This work was supported by grants 10/2 211311 from Carnot Institute (Ifremer Edrome)

\section{References}

[1] F. Wang, P.M. Chapman, Environmental Toxicology and Chemistry, 18 (2009) 2526-2532. [2] J.M. Brooks, M.C. Kennicutt, C.R. Fisher, S.A. Macko, K. Cole, J.J. Childress, R.R. Bidigare, R.D. Vetter, Science, 238 (1987) 1138-1142.

[3] J.J. Childress, C.R. Fisher, Oceanography and Marine Biology, 30 (1992) 337-441.

[4] D. Dyrssen, Marine Chem., 24 (1988) 143-153.

[5] G.W. Luther, T.F. Rozan, M. Taillefert, D.B. Nuzzio, C. Di Meo, T.M. Shank, R.A. Lutz, S.C. Cary, Nature, 410 (2001) 813-816.

[6] N. Le Bris, P.M. Sarradin, J.C. Caprais, Deep Sea Research Part I: Oceanographic Research Papers, 50 (2003) 737-747.

[7] V.P. Edgcomb, S.J. Molyneaux, M.A. Saito, K. Lloyd, S. Böer, C.O. Wirsen, M.S. Atkins, A. Teske, Applied and environmental microbiology, 70 (2004) 2551-2555.

[8] J.D. Cline, Limnology and Oceanography, (1969) 454-458.

[9] C.M. Sakamoto-Arnold, K.S. Johnson, C.L. Beehler, Limnology and Oceanography, (1986) 894-900.

[10] N. Le Bris, P.M. Sarradin, D. Birot, A.M. Alayse-Danet, Marine Chem., 72 (2000) 1-15.

[11] R. Vuillemin, D. Le Roux, P. Dorval, K. Bucas, J. Sudreau, M. Hamon, C. Le Gall, P. Sarradin, Deep Sea Research Part I: Oceanographic Research Papers, 56 (2009) 1391-1399.

[12] J. Radford-Knoery, G.A. Cutter, Analytical Chemistry, 65 (1993) 976-982.

[13] S. Peiffer, T. Frevert, Analyst, 112 (1987) 951-954.

[14] P. Jeroschewski, C. Steuckart, M. Kühl, Anal. Chem., 68 (1996) 4351-4357.

[15] P.J. Brendel, G.W.I.I.I. Luther, Environmental Science \& Technology, 29 (1995) 751-761.

[16] T.J. Waite, C. Kraiya, R.E. Trouwborst, S. Ma, G.W. Luther III, Electroanalysis, 18 (2006) 1167-1172.

[17] I. Ciglenečki, Z. Kodba, B. Ćosović, Marine Chem., 53 (1996) 101-110.

[18] G.W. Luther, T. Ferdelman, E. Tsamakis, Estuaries and Coasts, 11 (1988) 281-285.

[19] R. Al-Farawati, C.M.G. van den Berg, Marine Chem., 57 (1997) 277-286.

[20] Z. Bi, C.S. Chapman, P. Salaün, C.M.G. van den Berg, Electroanalysis, 22 (2010) 28972907.

[21] K. Gibbon-Walsh, P. Salaun, C.M.G. Van Den Berg, The Journal of Physical Chemistry A, (2012).

[22] C.S. Chapman, C.M.G. van den Berg, Electroanalysis, 19 (2007) 1347-1355.

[23] R.M. Town, H.P. van Leeuwen, Journal of Electroanalytical Chemistry, 509 (2001) 58-65. [24] H. Eskilsson, C. Haraldsson, D. Jagner, Analytica Chimica Acta, 175 (1985) 79-88. 
[25] J. Wang, D. Larson, N. Foster, S. Armalis, J. Lu, X. Rongrong, K. Olsen, A. Zirino, Analytical Chemistry, 67 (1995) 1481-1485.

3 [26] R.D. Riso, M. Waeles, S. Garbarino, P. Le Corre, Analytical and bioanalytical chemistry, $4379(2004) 1113-1119$. chemistry, 385 (2006) 76-82.

[28] P. Salaün, B. Planer-Friedrich, C.M.G. Van den Berg, Analytica chimica acta, 585 (2007) 312-322.

[29] V. Tanguy, M. Waeles, J. Vandenhecke, R. Riso, Talanta, 81 (2010) 614-620.

[30] A. Manova, M. Strelec, F. Cacho, J. Lehotay, E. Beinrohr, Analytica chimica acta, 588 (2007) 16-19.

[31] M. Budd, H. Bewick, Analytical Chemistry, 24 (1952) 1536-1540.

[32] P.-M. Sarradin, M. Waeles, S. Bernagout, C. Le Gall, J. Sarrazin, R. Riso, Science of The Total Environment, 407 (2009) 869-878.

[33] E. Suess, D. Wallschlager, B. Planer-Friedrich, Chemosphere, (2011).

[34] L.R. Goodwin, D. Francom, A. Urso, F.P. Dieken, Analytical Chemistry, 60 (1988) 216219.

[35] L. Nyholm, G. Wikmark, Analytica Chimica Acta, 257 (1992) 7-13.

[36] K. Gibbon-Walsh, P. Salaün, M.K. Uroic, J. Feldmann, J.M. McArthur, C.M.G. Van den Berg, Talanta, (2011).

[37] P. Salaün, C.M.G. van den Berg, Analytical chemistry, 78 (2006) 5052-5060.

[38] R.M. Town, H.P. van Leeuwen, Journal of Electroanalytical Chemistry, 523 (2002) 1-15.

[39] C. Hua, D. Jagner, L. Renman, Analytica chimica acta, 197 (1987) 257-264.

[40] D. Jagner, L. Renman, S.H. Stefansdottir, Analytica Chimica Acta, 281 (1993) 305-314.

[41] E. Bura-Nakic, A. Róka, I. Ciglenecki, G. Inzelt, Journal of Solid State Electrochemistry, 13 (2009) 1935-1944.

[42] K.Y. Chen, J.C. Morris, Environmental Science \& Technology, 6 (1972) 529-537.

[43] F.J. Millero, Deep Sea Research Part A. Oceanographic Research Papers, 38, Supplement 2 (1991) S1139-S1150.

[44] F.J. Millero, A. LeFerriere, M. Fernandez, S. Hubinger, J.P. Hershey, Environmental science \& technology, 23 (1989) 209-213.

[45] Z. Jia-Zhong, M. Whitfield, Marine Chem., 19 (1986) 121-137.

[46] Y. He, Y. Zheng, D.C. Locke, Analytica Chimica Acta, 459 (2002) 209-217.

[47] F.J. Millero, S. Hubinger, M. Fernandez, S. Garnett, Environ. Sci. Technol., 21 (1987) 439443.

[48] E.R. DeLeon, G.F. Stoy, K.R. Olson, Analytical Biochemistry, 421 (2012) 203-207.

[49] X. Gao, Y. Zhang, M.J. Weaver, Langmuir, 8 (1992) 668-672.

[50] J. Buffle, G. Horvai, In Situ Monitoring of Aquatic Systems: Chemical Analysis and Speciation, New Ed., John Wiley \& Sons Ltd, 2001.

[51] P. Lustemberg, C. Vericat, G. Benitez, M. Vela, N. Tognalli, A. Fainstein, M. Martiarena, R. Salvarezza, The Journal of Physical Chemistry C, 112 (2008) 11394-11402.

[52] C. Gru, H. Legoff, S. Narcon, P.M. Sarradin, J.C. Caprais, F.H. Lallier, Analyst, 123 (1998) 1289-1293.

[53] G.W. Luther III, B.T. Glazer, L. Hohmann, J.I. Popp, M. Taillefert, T.F. Rozan, P.J. Brendel, S.M. Theberge, D.B. Nuzzio, J. Environ. Monit., 3 (2001) 61-66. 


\section{Tables}

2

3 Table 1: Influence of addition of thioacetic acid $\left(\mathrm{CH}_{3} \mathrm{COSH}\right)$, glutathione $(\mathrm{GSH})$ and elemental

4 sulfur $\left(S^{0}\right)$ on sulfide signal. Initial sulfide concentration: $1.0 \mu \mathrm{M}$. Each determination was

5 realized in duplicate and is given with the standard deviation

6

7

\begin{tabular}{|l|l|l|l|}
\hline Concentration factor & $\mathrm{CH}_{3} \mathrm{COSH}$ & $\mathrm{GSH}$ & $\mathrm{S}$ \\
\hline 0 & $100 \pm 2 \%$ & $100 \pm 5 \%$ & $100 \pm 2 \%$ \\
\hline 1 & $91 \pm 18 \%$ & $12 \pm 15 \%$ & $90 \pm 35 \%$ \\
\hline 10 & $31 \pm 17 \%$ & $\mathrm{u}$ & $103 \pm 34 \%$ \\
\hline 100 & $\mathrm{u}$ & $\mathrm{u}$ & $93 \pm 15 \%$ \\
\hline
\end{tabular}

u : undetectable 


\section{Figure captions}

3 Fig. 1: a) Stability of sulfide (initial concentration, $13 \mu \mathrm{M}$ ) in $0.5 \mathrm{M} \mathrm{NaCl}$, seawater at natural

$4 \mathrm{pH}$ and seawater buffered at $\mathrm{pH} 9.6$ with $0.01 \mathrm{M} \mathrm{NH}_{4} \mathrm{OH}$ and $0.01 \mathrm{M} \mathrm{NH}_{4} \mathrm{Cl}$. b) In (peak area)

5 as a function of time for testing first order kinetic (only $\mathrm{NaCl} 0.5 \mathrm{M}$ is presented).

6 Electrochemical conditions: $E_{d}=-0,25 \mathrm{~V} ; t_{d}=10 \mathrm{~s}$ (without vibration); $i=-2 \mu \mathrm{A} . \quad E_{c}=-$ $7 \quad 1.1 \mathrm{~V} ; \mathrm{t}_{\mathrm{c}}=10 \mathrm{~s}$

8 Fig. 2: a) Influence of deposition potential on free sulfide stripping signal. b) typical stripping

9 signals obtained with $E_{d}=-0.45 V, E_{d}=-0.25 V$ and $E_{d}=0.15 V$. The black arrow indicates the position of the sulphide peak. Unaltered hydrothermal sample. Electrochemical conditions:

$11 t_{d}=7 \mathrm{~s}$ (with vibration); $\mathrm{i}=-2 \mu \mathrm{A} ; \mathrm{E}_{\mathrm{c}}=-1.1 \mathrm{~V} ; \mathrm{t}_{\mathrm{c}}=10 \mathrm{~s}$.

Fig. 3: a) Influence of stripping current on free sulfide stripping signal. b) typical stripping signal obtained with $\mathrm{i}_{\mathrm{s}}=-0.3 \mu \mathrm{A}$. c) typical stripping signal obtained with $\mathrm{i}_{\mathrm{s}}=-0.2 \mu \mathrm{A}$. Unaltered Hydrothermal samples. Electrochemical conditions: $t_{d}=7 \mathrm{~s}$ (with vibration); $E_{d}=-0.25 V ; E_{c}=-$ $1.1 \mathrm{~V} ; \mathrm{t}_{\mathrm{c}}=10 \mathrm{~s}$

Fig. 4: Influence of sulfide concentrations on stripping signal a) sulfide concentrations in the range $0-20 \mu \mathrm{M}$; b) sulfide concentrations in the range $0-2 \mu \mathrm{M}$. Unaltered hydrothermal samples. Electrochemical conditions: $t_{d}=7 \mathrm{~s}$ (with vibration) ; $E_{d}=-0.25 \mathrm{~V} ; \mathrm{E}_{c}=-1.1 \mathrm{~V} ; \mathrm{t}_{c}=10 \mathrm{~s}$. For experiment presented in $b)$, mean $\pm S D(n=4)$

Fig. 5: Example of sulfide determination in a hydrothermal sample (Lucky Strike vent field)

21 under optimized parameters: $t_{d}=7 \mathrm{~s}$ (with vibration); $E_{d}=-0.25 V ; E_{c}=-1.1 V ; t_{c}=10 \mathrm{~s}$. Obtained concentration: $210 \mathrm{nM}$. 
Figure 1
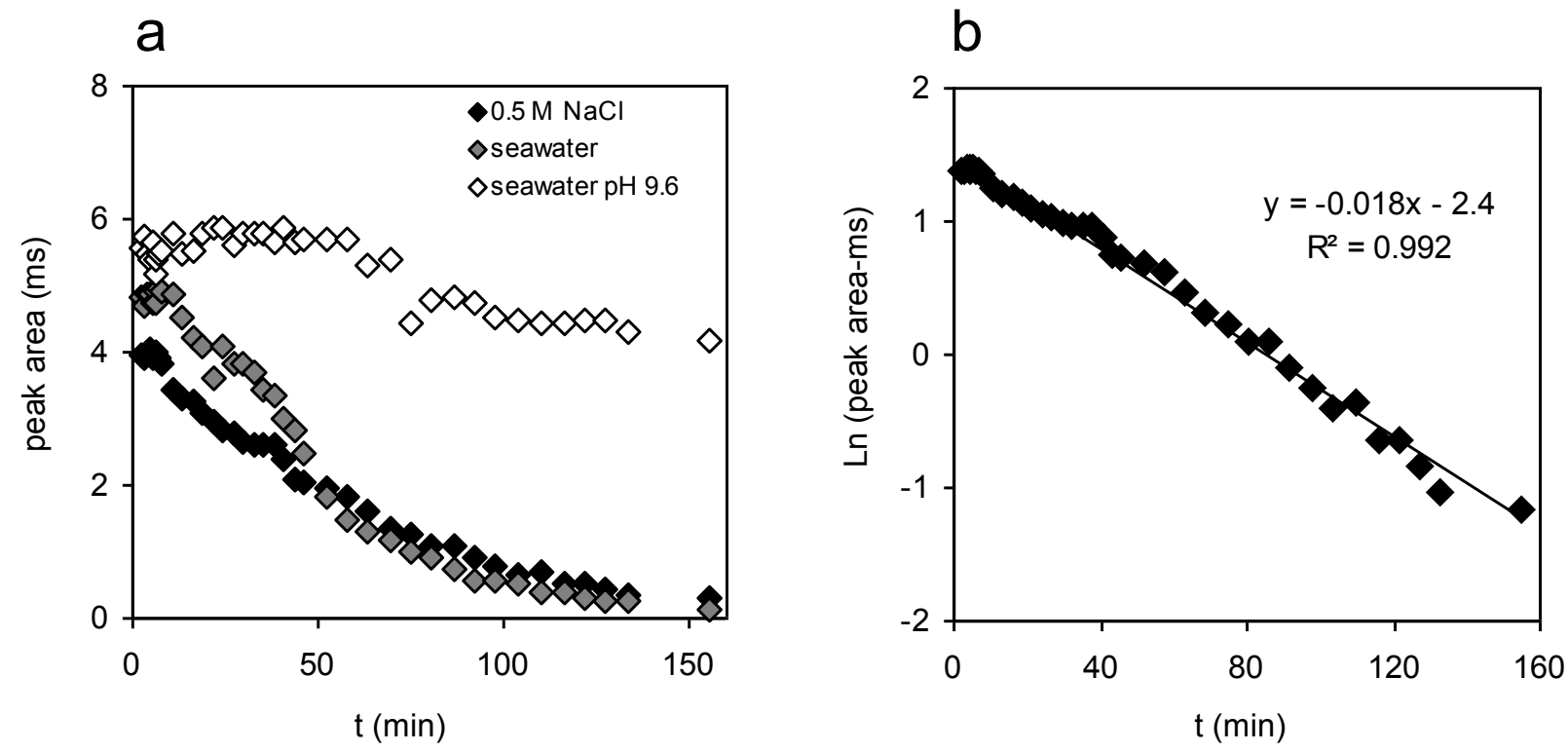
Figure 2
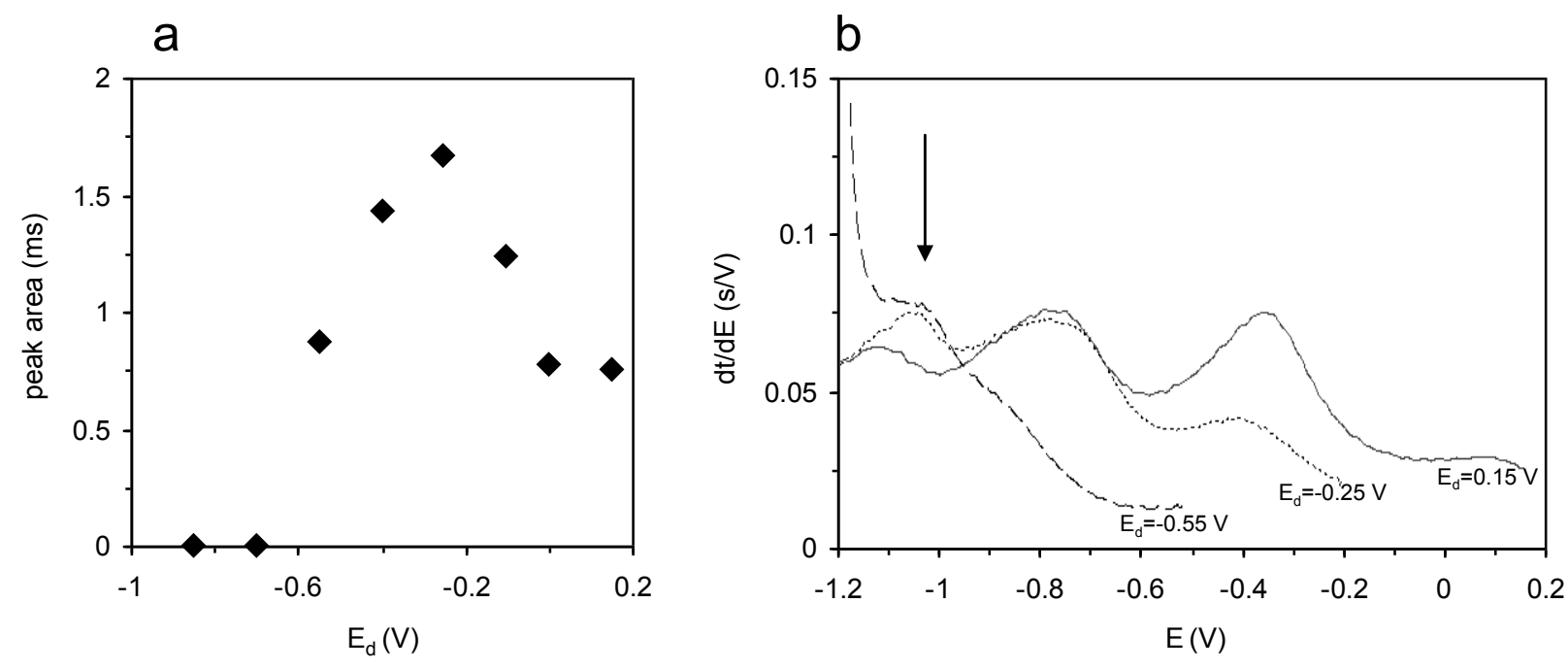
Figure 3
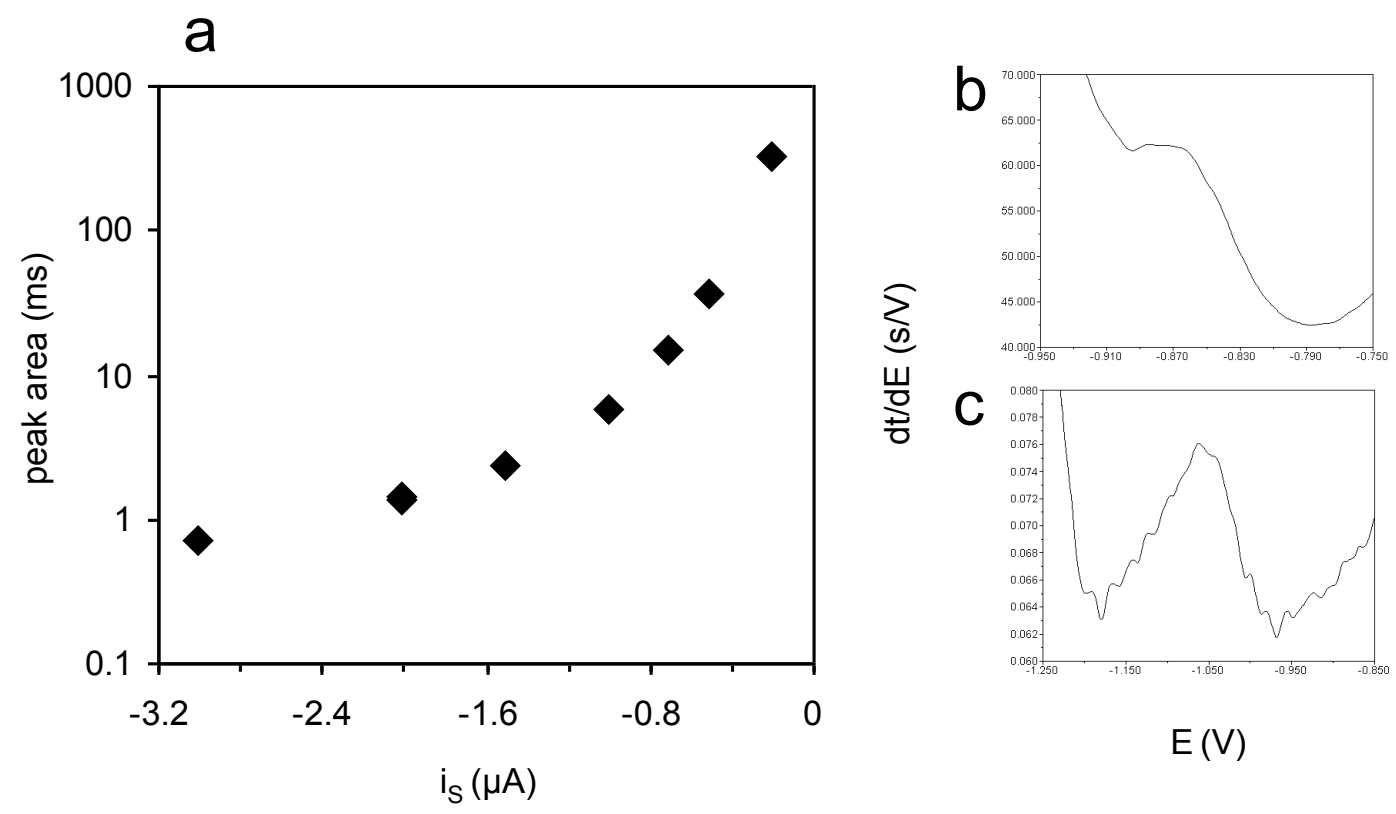


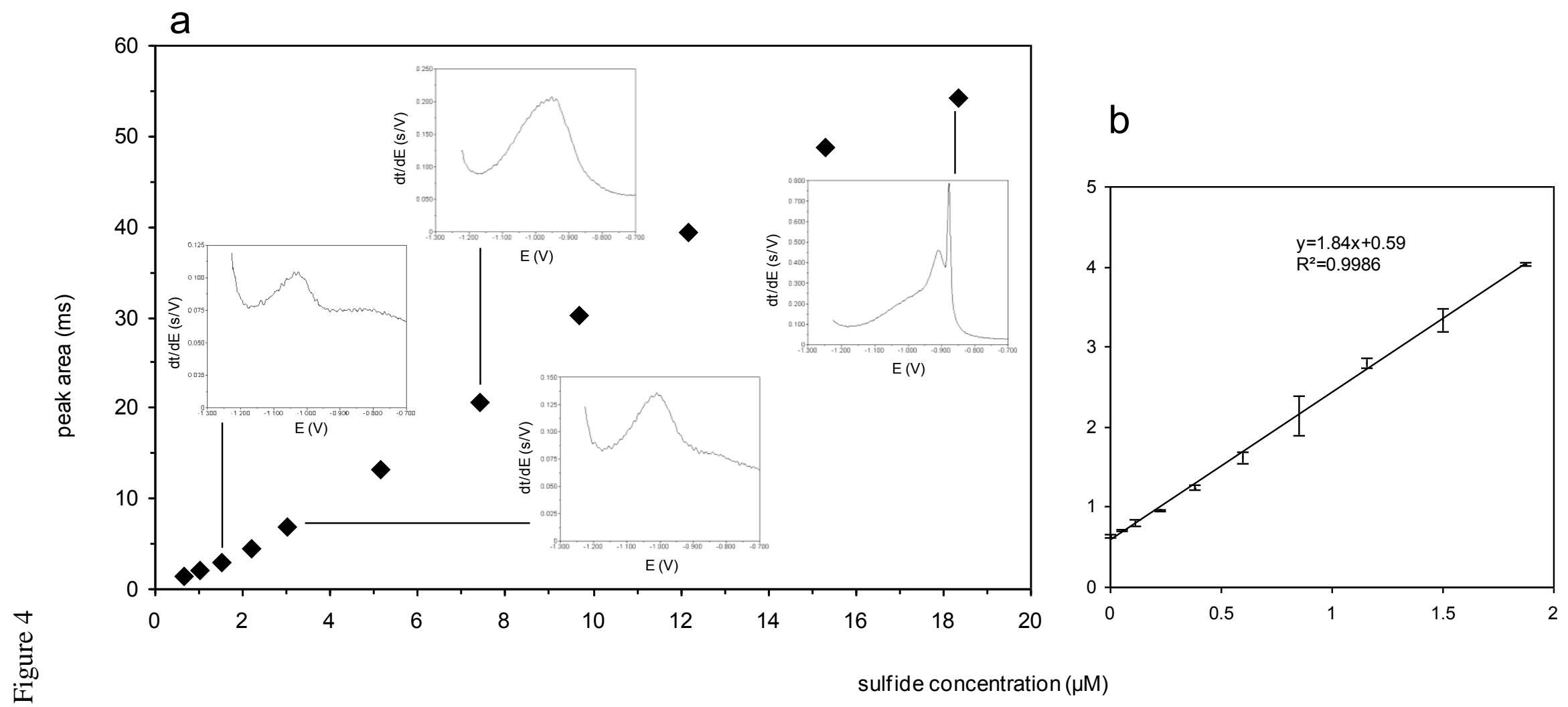


Figure 5

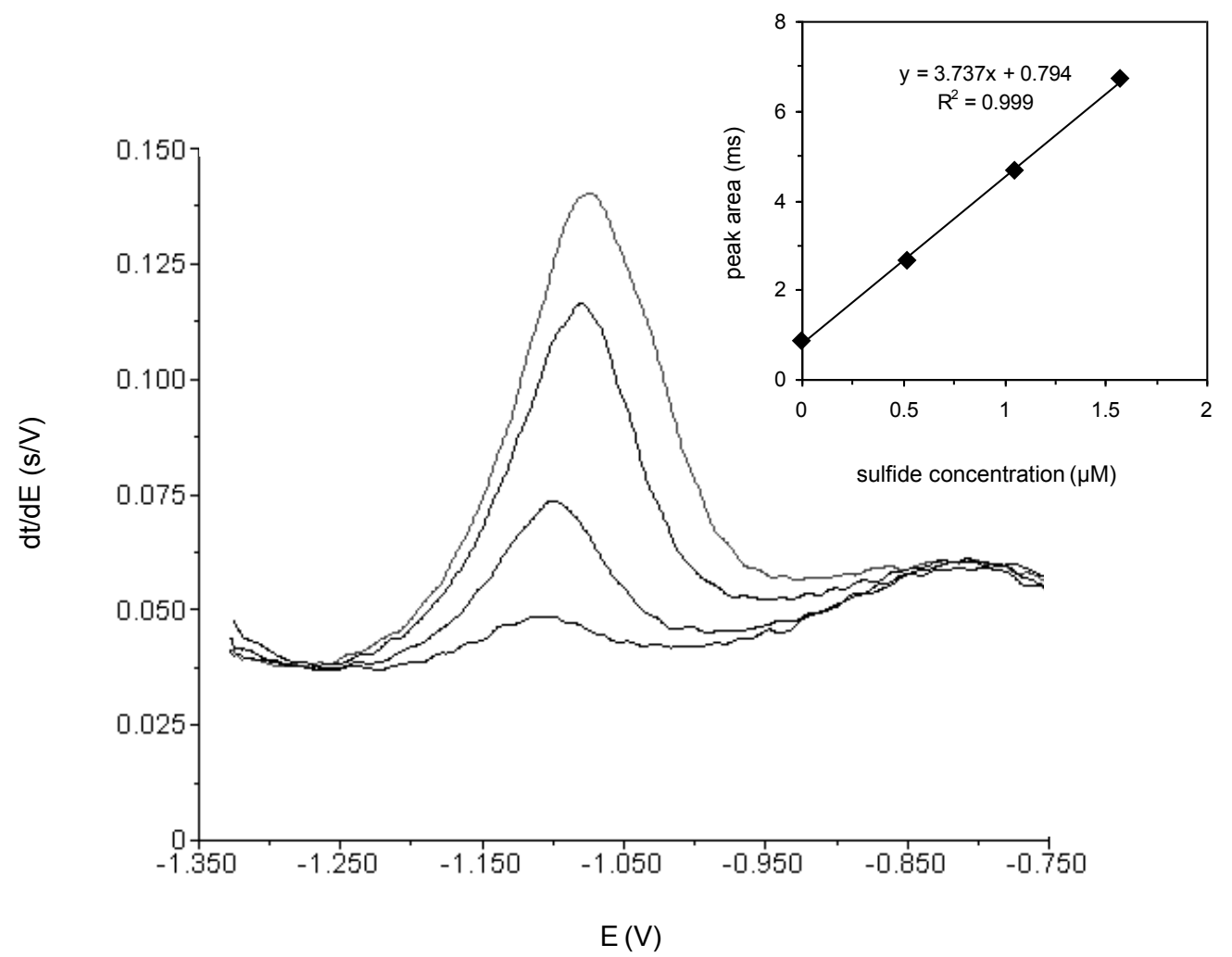

